\title{
Innovation Contests: How to Design for Successful Idea Selection
}

\author{
Christina \\ Sarigianni ${ }^{1}$

\begin{abstract}
Victoria
Banken $^{1}$
\end{abstract} \\ Renata \\ Arnold \\ Santiago Walser ${ }^{1} \quad$ Wibmer $^{1}$ \\ Frederik \\ Wiedmann ${ }^{1}$ \\ Isabella \\ Seeber ${ }^{1}$ \\ ${ }^{1}$ University of Innsbruck, Austria [firstname.lastname]@uibk.ac.at
}

\begin{abstract}
Innovation contests provide several benefits, but many organizations struggle with managing emergent challenges that occur during the idea selection process. This paper builds on qualitative interviews, where practitioners shared their experiences with managing innovation contests. Across the 13 contest domains studied in 31 cases, we identified five frequently occurring contest goals: (1) promote entrepreneurship, (2) collect innovative ideas, (3) elevate awareness, (4) explore market opportunities, and (5) find talent that influence the design of the selection process. Moreover, for five common emergent challenges we identified how practitioners apply manual and IT-enabled coping strategies, which can be associated with three design elements, i.e., the (1) ideas for the innovation, the (2) raters of the ideas, and the (3) duration of the selection process. These findings are summarized in a guiding framework that helps practitioners design, navigate, and manage the complex process of idea selection.
\end{abstract}

\section{Introduction}

According to recent studies, $84 \%$ of executives consider their business success to be dependent on innovation [1]. But how do businesses drive innovation? Businesses can adopt open innovation initiatives, which are activities to source innovative ideas from users or agents outside and inside organizational boundaries, or closed innovation initiatives, which refer to innovation processes traditionally performed in R\&D departments [2]. This paper focuses on open innovation, where businesses rely on external expertise to develop new products and services instead of fully executing the entire innovation process in the R\&D department [3].

The benefits of open innovation are twofold. First, open innovation enables firms to boost their overall performance [4]. By leveraging external sources, organizations have the opportunity to identify the ideas that fit best to their current needs, drive internal growth [5] and enhance their competitive advantage [4]. Furthermore, open innovation enables the ideators to show their talent [6-8] and obtain various benefits like enjoyment and learning, gain reputation, and win monetary rewards $[9,10]$.

While highly beneficial, open innovation initiatives certainly require significant effort and resources to return the expected value. According to [1], more than half of the organizations that rely on open innovation fail to bridge the gap between their innovation strategy and the broader business strategy. Why is that? While we know that a well-managed idea generation phase can result in the generation of many high-quality ideas [11], idea selection can be that challenging that high-quality ideas do not make it on the shortlist [12]. A main reason is the high cognitive demand [13] imposed on and the limited cognitive resources of raters, which may result in cognitive overload [14] and consequently, in poor selection performance [15]. Thus, selection performance may not be considerably higher than chance [16-18], which makes the effective management of the selection processes a top challenge of open innovation [19].

Multiple methods are suggested to improve the selection process and solve emerging problems, but they are often manual [13] and effortful. The recent advances in machine learning techniques may offer new opportunities to automate categorization and classification tasks. Advances in natural language processing provide unique opportunities to scale communication tasks [20]. However, we know little what IT-enabled strategies organizations adopt to counteract emergent challenges during idea selection.

The purpose of this paper is to provide recommendations in the form of a guiding framework that helps practitioners manage the design of idea selection processes and cope with emergent challenges. In the current study, we draw on 34 interviews with contest managers in 31 unique cases that provide their perspective on what to consider during idea selection (Section 2). We identified five context goals that offer holistic insights into WHY practitioners run open innovation initiatives (Section 3). We also found prominent design elements that characterize the 
selection process and allow to deduce WHAT to consider when designing the selection process. We uncovered HOW practitioners solve selection challenges that commonly emerge (Section 4). We conclude by summarizing these findings into a guiding framework (Section 5).

\section{About the Innovation Contests}

We conducted 34 semi-structured interviews between May 2017 and March 2018 in 31 unique case settings. As Table 1 depicts, 9 cases reported on startup challenges, 4 cases were student challenges, and the remaining 18 cases were idea contests in 11 different domains. The studied innovation contests differed in terms of their size (22 ideas to 5116 ideas), their involvement of raters, their durations for converging on ideas ( 0.5 to 104 days), their goals for the contest, and the challenges they experienced. Please refer to the Appendix for more details on the research methodology.

\section{Why do organizations run innovation contests?}

Contest organizers have diverse goals when they run an innovation contest, and these influence the management of idea selection. Our interviewees reported on five contest goals that explain why practitioners engage in such open innovation initiatives: "collecting innovative idea(s)", "promote entrepreneurship", "elevate awareness", "explore market opportunities", and "find talent(s)".

One of the most widely recognized contest goal (13 cases) was collecting innovative idea(s). Contest

Table 1: Case overview

\begin{tabular}{|c|c|c|c|c|c|c|c|c|c|c|c|c|c|c|}
\hline \multirow[b]{2}{*}{$\begin{array}{c}\text { Case } \\
\text { ID }\end{array}$} & \multirow[b]{2}{*}{ Contest domain } & \multirow{2}{*}{ 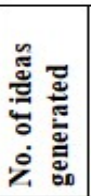 } & \multirow{2}{*}{ 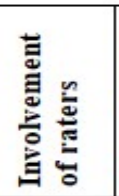 } & \multirow{2}{*}{ 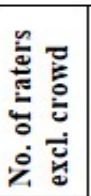 } & \multirow[b]{2}{*}{ 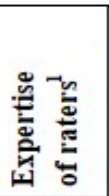 } & \multirow{2}{*}{ 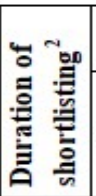 } & \multicolumn{5}{|c|}{ Goal $^{3}$} & \multicolumn{3}{|c|}{$\begin{array}{c}\text { Challenges } \\
\text { related to }\end{array}$} \\
\hline & & & & & & & $\%$ & ९ & 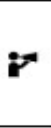 & Q & 298 & $\stackrel{n}{\tilde{E}}$ & 离 & 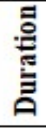 \\
\hline $\mathrm{A}$ & sustainable development & 70 & internal & \begin{tabular}{|r|}
6 \\
\end{tabular} & $E, G$ & 1.5 & & & $\mathrm{x}$ & $\mathrm{x}$ & & & $\mathrm{x}$ & \\
\hline $\mathrm{B}$ & sustainable development & 172 & both & 10 & $\mathrm{E}, \mathrm{G}$ & $\mathrm{n} / \mathrm{a}$ & & & $\mathrm{x}$ & & & & $\mathrm{x}$ & \\
\hline $\mathrm{C}$ & mobility & 104 & internal & $\mathrm{n} / \mathrm{a}$ & $\mathrm{G}, \mathrm{N}$ & 9 & $\mathrm{x}$ & $\mathrm{x}$ & & & & $\mathrm{x}$ & & \\
\hline $\mathrm{D}$ & mobility & 633 & internal & 8 & $\mathrm{E}, \mathrm{G}, \mathrm{N}$ & 96 & $\mathrm{x}$ & $\mathrm{x}$ & $\mathrm{x}$ & & & $\mathrm{x}$ & $\mathrm{x}$ & $\mathrm{x}$ \\
\hline $\mathrm{E}$ & gender equality & 91 & both & 9 & $\mathrm{E}, \mathrm{G}, \mathrm{N}$ & 49 & & & $\mathrm{x}$ & & & $\mathrm{x}$ & & $\mathrm{x}$ \\
\hline $\mathrm{F}$ & aerospace & 5116 & both & 5 & $\mathrm{G}$ & 42 & & $\mathrm{x}$ & & & & $\mathrm{x}$ & $\mathrm{x}$ & \\
\hline $\mathrm{G}$ & regional development & 120 & both & 2 & $\mathrm{E}, \mathrm{N}$ & 6 & $\mathrm{x}$ & & & & & $\mathrm{x}$ & $\mathrm{x}$ & \\
\hline I & high tech & 396 & both & 10 & $\mathrm{E}, \mathrm{N}$ & 21 & & $\mathrm{x}$ & & & & $\mathrm{x}$ & $\mathrm{x}$ & \\
\hline $\mathrm{J}$ & aerospace & 700 & internal & 70 & $\mathrm{E}, \mathrm{G}$ & 14 & & & & & $\mathrm{x}$ & $\mathrm{x}$ & & \\
\hline $\mathrm{K}$ & development aid & 478 & $\mathrm{n} / \mathrm{a}$ & $\mathrm{n} / \mathrm{a}$ & $\mathrm{n} / \mathrm{a}$ & 14 & & $\mathrm{x}$ & & & & $\mathrm{x}$ & $\mathrm{x}$ & \\
\hline $\mathrm{L}$ & university & 120 & internal & 40 & $E$ & 42 & & $\mathrm{x}$ & & & & $\mathrm{x}$ & $\mathrm{x}$ & \\
\hline M & lighting engineering & 160 & internal & 7 & $\mathrm{E}$ & 17.5 & & & $\mathrm{x}$ & $\mathrm{x}$ & & & $\mathrm{x}$ & \\
\hline $\mathrm{N}$ & education & 105 & internal & 7 & $\mathrm{E}, \mathrm{G}$ & 42.5 & & $\mathrm{x}$ & $\mathrm{x}$ & $\mathrm{x}$ & & $\mathrm{x}$ & $\mathrm{x}$ & $\mathrm{x}$ \\
\hline $\mathrm{O}$ & aerospace & 57 & both & 9 & $\mathrm{E}, \mathrm{N}$ & 14.5 & & $\mathrm{x}$ & & & & $\mathrm{x}$ & $\mathrm{x}$ & $\mathrm{x}$ \\
\hline $\mathrm{P}$ & mobility & 420 & internal & 20 & $\mathrm{E}$ & 43 & $\mathrm{x}$ & & & & & $\mathrm{x}$ & $\mathrm{x}$ & \\
\hline$Q$ & high tech & 405 & internal & 12 & $\mathrm{E}$ & 0.5 & & $\mathrm{x}$ & & & & $\mathrm{x}$ & $\mathrm{x}$ & $\mathrm{x}$ \\
\hline $\mathrm{R}$ & sustainable development & 40 & both & 3 & $\mathrm{E}, \mathrm{G}$ & $\mathrm{n} / \mathrm{a}$ & $\mathrm{x}$ & & & & & $\mathrm{x}$ & $\mathrm{x}$ & \\
\hline $\mathrm{S}$ & startup & 22 & internal & 5 & $\mathrm{E}$ & 17.5 & $\mathrm{x}$ & & & & & $\mathrm{x}$ & $\mathrm{x}$ & \\
\hline $\mathrm{T}$ & startup & 45 & internal & 4 & $\mathrm{E}, \mathrm{G}$ & 24.5 & $\mathrm{x}$ & & & $\mathrm{x}$ & & $\mathrm{x}$ & $\mathrm{x}$ & \\
\hline $\mathrm{U}$ & startup & 250 & internal & 2 & $\mathrm{G}$ & 43.75 & $\mathrm{x}$ & & & & & $\mathrm{x}$ & & \\
\hline $\mathrm{V}$ & startup & 70 & $\mathrm{n} / \mathrm{a}$ & $\mathrm{n} / \mathrm{a}$ & $\mathrm{n} / \mathrm{a}$ & $\mathrm{n} / \mathrm{a}$ & $\mathrm{x}$ & & & & & $\mathrm{x}$ & & \\
\hline W & startup & 140 & both & 12 & $\mathrm{E}, \mathrm{G}$ & 105 & $\mathrm{x}$ & & & & & $\mathrm{x}$ & $\mathrm{x}$ & \\
\hline $\mathrm{X}$ & startup & 240 & internal & 5 & $\mathrm{E}, \mathrm{G}$ & 14 & $\mathrm{x}$ & & & & & $\mathrm{x}$ & $\mathrm{x}$ & \\
\hline $\mathrm{Y}$ & startup & 250 & external & 170 & $E$ & 21 & $\mathrm{x}$ & & & & & $\mathrm{x}$ & $\mathrm{x}$ & \\
\hline $\mathrm{Z}$ & startup & 89 & internal & 12 & $\mathrm{E}, \mathrm{G}$ & 3 & $\mathrm{x}$ & & $\mathrm{x}$ & & & & $\mathrm{x}$ & \\
\hline A.A & students & 20 & both & 3 & $\mathrm{E}, \mathrm{G}$ & 1.5 & $\mathrm{x}$ & $\mathrm{x}$ & $\mathrm{x}$ & & $\mathrm{x}$ & $\mathrm{x}$ & $\mathrm{x}$ & \\
\hline$A B$ & students & 75 & internal & 135 & $\mathrm{~N}$ & 0.5 & & $\mathrm{x}$ & $\mathrm{x}$ & & $\mathrm{x}$ & $\mathrm{x}$ & $\mathrm{x}$ & \\
\hline $\mathrm{AC}$ & students & 100 & internal & 4 & $\mathrm{E}, \mathrm{G}$ & 4.5 & & & & & $\mathrm{x}$ & $\mathrm{x}$ & $\mathrm{x}$ & \\
\hline $\mathrm{AD}$ & students & 24 & both & 2 & $\mathrm{E}, \mathrm{G}$ & 24.5 & & $\mathrm{x}$ & & & & $\mathrm{x}$ & $\mathrm{x}$ & \\
\hline $\mathrm{AE}$ & news & 5000 & both & 17 & $\mathrm{E}, \mathrm{G}$ & 1 & & $\mathrm{x}$ & & $\mathrm{x}$ & & $\mathrm{x}$ & & \\
\hline $\mathrm{AF}$ & startup & 25 & both & 3 & $\mathrm{E}, \mathrm{G}$ & 104 & $\mathrm{x}$ & & & & & & $\mathrm{x}$ & $\mathrm{x}$ \\
\hline \multicolumn{15}{|c|}{${ }^{1} \mathrm{E}=$ domain experts, $\mathrm{G}=$ Generalists, $\mathrm{N}=$ Novices } \\
\hline${ }^{3} \%$ & $\begin{array}{l}=\text { Promote entrepreneursl } \\
=\text { Explore market opportu }\end{array}$ & $\begin{array}{l}\text { nities } \\
\text { nies }\end{array}$ & $\begin{array}{l}=\text { Collect } \\
g:=\text { Fin }\end{array}$ & $\begin{array}{l}\text { innova } \\
\text { ad talent }\end{array}$ & tive idea & & & & & & & & & \\
\hline
\end{tabular}


organizers adopt this goal when they seek to find a solution to a given problem: "The goal was to identify innovative news media solutions." (AE) or to investigate application areas of products under development: "The objective was clearly that you can identify use cases.” (Q). Organizations that wanted to improve rigid processes, like bringing products faster to the market, are also subsumed under this goal: "Our development cycles are more likely to last four years. So that was also a goal to show that in such an area, where it is about an E-Pad, it can be faster." (D). Also, the intention to foster innovativeness, by obtaining inspirations and encouraging out-of-the-box-thinking for disruptive innovations is a characteristic of this goal: "[...] for us it's great to see that a topic is sometimes seen from different perspectives and not just the analysts' perspectives." (AB).

Almost half of our studied contest cases strived to promote entrepreneurship (15 cases) in addition to other contest goals (e.g., collecting innovative ideas) or as a mere focus. The organizations that pursued this objective aimed at supporting contributors or start-ups in their business practices: "[...] to offer the best possible support to get them [the ideas] into the race." (G). Primary focus in this context involved the support through business-trainings and mentoring activities in early stages: "The aim was actually to mobilize the start-up activities [...] It's actually very much about mobilizing and giving support to as many people as possible on their entrepreneurial path." (Y). Some contest organizers also offered networking opportunities as part of the contest, which allowed to-be entrepreneurs to exchange ideas and learn from each other. "It has become such a good community, and many people have networked and wanted to work together." (D). Another form of achieving this goal related to enhancing the ideators' publicity and foster traction: "[...] to give start-ups in developing countries the opportunity to attract global attention." (R). Finally, contest organizers relied on matching the contributors with potential investors, generating mutual benefits for both parties to achieve this goal: "Our expectation is that it will be a very positive event for both sides, for the start-ups and the investors, which means that there will be deals." (X).

Organizations also set up open innovation initiatives to elevate awareness (9 cases) about a particular topic or area. According to our study participants, innovation contests were deployed as a marketing tool to enhance the brand name: "They really want to use crowdsourcing as a marketing instrument." (N). In other cases, the focus was to build a community around the organizer of the contest: "The aim is community building around the topic of social entrepreneurship." (Z). Besides, contests were also conducted to promote a specific topic or concern. For example, a car manufacturer held a contest to increase awareness on the subject of mobility: "Our goal was actually to create awareness for this mobility topic." (D).

When contest organizers set the goal to explore market opportunities (5 cases), they were more interested in receiving future business-relevant information rather than collecting ideas as a concrete solution to a problem. Thus, the innovation contest was utilized to identify trends: "We use innovation contests not so much to end up with one awesome solid idea, but as a tool for collecting things and trends that are going on" (AE), or customer needs: "if there are problems that people have with the way they consume media and how they could potentially provide a solution for that." (AE).

Organizations also used innovation contests to find talent(s) (4 cases), to form and promote motivated groups of innovative thinkers and drive innovation within a company: "The purpose of this campaign was not to select ideas, the purpose of this campaign was to identify talents." (J).

Figure 1 summarizes the five identified contest goals ordered by the frequency of each goal mentioned. But why is it important to be aware of these goals? Generally, we observed that most contest organizers have an overarching goal that drives the innovation initiative. This goal demonstrates a clear vision of what they want to achieve with an innovation contest. The mere specification of the contest goal(s) is not enough, but also needs to come along with a clear challenge description and a definition of relevant evaluation criteria. Otherwise, organizations run the risk that contributors generate ideas that do not solve their problem or that raters discard ideas even though they would have fit their vision. Further goals that might be pursued on the side are either a "nice to have" outcome that complements the initial goal or emerge during the innovation contest.

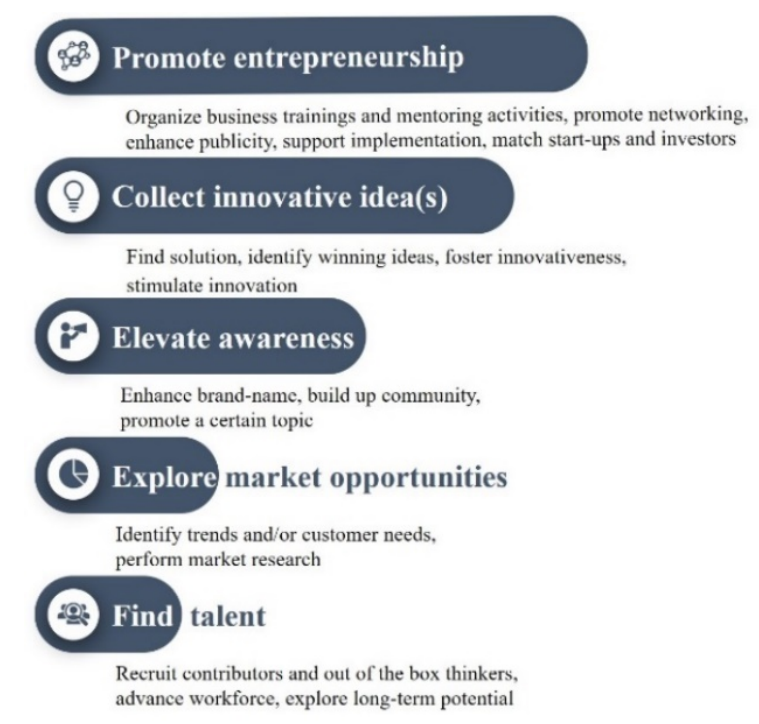

Figure 1. Contest goals 


\section{How do organizations deal with emergent challenges?}

The introduced contest goal(s) are essential for idea selection as they provide a vision of what kind of ideas the organization deems good or not. For example, the CEO of a contest host reported that "there were several solutions they didn't want or that they already had" (F). However, several other design elements (i.e., a combination of common design features of contests [21]) exist that influence the complex process of idea selection. This paper contributes three common design elements, “ideas"”, "raters", and "duration" that organizations deployed for their idea selection processes. These design elements are very much in line with the "degree of elaboration", "evaluation" and "contest period" suggested by [21], but partly differ in their specific characteristics. Challenges can emerge fast despite a well-thought-through selection process design. Hence, we provide insights into prominent challenges that emerged during the idea selection process and the ad hoc coping strategies that organizations implemented. The majority of the coping strategies required manual work, extra time, and additional resources. To decrease manual work and resource expenditure, our interviewees recommended several functionalities, which are either already implemented or would provide appropriate IT support. We argue that such automated solutions could most likely tackle some of the challenges when concrete goals are set. Thus, we suggest how technology can facilitate the digitalization of the idea selection process.

\subsection{Design element “ideas”}

Design element. The first design element "ideas" refers to the design of the steps in selection processes depending on the quantity and quality of ideas submitted to a contest. While most organizations had a plan ready for how to engage in selection, they often had to redesign their selection process depending on the quantity and quality of ideas they received. Related to this design element "ideas", we identified high quantity of ideas and poor idea description as the major emergent challenges.

Emergent challenge - high quantity of ideas. Our study participants provided rich insights on how they dealt with the number of submitted ideas and described how information overload occurred. The number of submitted ideas ranged between 20 and more than 5,000 ideas. In most cases, the size of the contest was independent of the contest goal an organization pursued. However, for contests with the goal to "collect innovative idea(s)", the number of submitted ideas tended to be bigger with a few hundred or more ideas.
In a case with the goal to "collect innovative idea(s)", the number of ideas submitted was so high that the contest's organizers were overwhelmed and faced difficulties how to manage the overwhelming amount of ideas: "We had 152 teams and a total of 5116 submissions. No one was expecting that many submissions and that many participants.” (F).

In other cases, the contest organizers explained that also the variety of idea content was overwhelming. While the number of submissions was rather low with 57 generated ideas, the actual content was hard to process as it included text, figures, community feedback, and several other attributes necessary for the evaluation. The contest organizers explained that such detailed descriptions quickly led to information overload: "One export from the platform has all the information, like the idea, title, description, evaluation criteria, average evaluation, evaluation from the community and experts, and number of views. We have much information." (O).

Coping strategies. To counteract the information overload and successfully deal with the number of ideas, the contest organizers turned to drastic solutions like immediate idea elimination according to required submission features. Specifically, a contest organizer described the detailed steps of the elimination process: "First things first, you look at, "were all of the questions answered?" and if there are any blank fields, then you're automatically eliminated. It's one quick step. The next step is that any submission that didn't include a design, because it was a design challenge and you had to submit a design, was reviewed in our database and eliminated." (F). Even though immediate elimination proved an efficient way for drastically reducing the number of ideas, it resulted in fear of missing out as the contest organizers were advised to repeat the evaluation process and ensure that nothing good has been left out: "That was actually a request from the client. They said, -we're getting a bit nervous here, we want to make sure that we did not eliminate anything good, so can you guys go back and run your elimination process again, and search for the specific keywords?" (F).

Alternatively, a way to counteract the information overload issue and manage the number of ideas was to restructure ideas manually. The contest organizers described how they dealt with the content of the submitted ideas through merging of similar ideas, splitting of diverse ideas in single submissions and content structuring. This strategy even though was time consuming, provided a good overview and assisted better evaluation in consequent steps: "When the ideation phase was over, when we had this critical amount of information, I structured and analyzed all [ideas] "ok, these ideas are about the same thing", so I try to merge, structure, split, or maybe rephrase them, 
so that they are like bullet points and easy to read and comprehend." (E).

Another solution was to manually cluster similar ideas so that they would be easily comparable within their category: "We clustered the ideas [...]. It really helped to compare these ideas within their cluster." (D).

IT features. To avoid the fear of missing out due to information overload, our interviewees proposed additional IT solutions that can enhance the quality and speed up the elimination process. By categorizing ideas, contest organizers can better manage the high number of ideas as raters have a more comprehensive overview of similar ideas. Categorization of ideas can be achieved through text mining techniques like keyword extraction (E, S, P) and clustering (AE, J). Some of our participants highlighted the usefulness of standardized submission forms (A, D, T) on the online submission platform that allow the easier application of these techniques and other relevant categorization and structuring methods (e.g., filtering). Successful structuring and categorization are associated with smarter allocation of ideas to the raters and alleviate the problems that arise due to the high number of ideas.

Emergent challenge - poor idea description. Apart from quantity issues, we also came across quality issues. The interviewees emphasized the challenge of how to deal with poor quality ideas. Poor quality ideas were either too short: "Some ideas were described very precisely or too briefly and a member of the jury who is not used to the topic can't evaluate that."(Q), poorly articulated: "There were ideas that had a concrete relevance to the common good, but were poorly formulated." (G), or not in line with the contest goal: "Sometimes there are applicants who don't really read through the criteria or just send [the idea] off." (U).

Interviewees argued that poor quality resulted from low motivation and a lack of creativity by the ideators. The interviewees expressed an apparent dissatisfaction and highlighted that the ideators should think through their ideas and consider the criteria before submission: "Well, there are just a lot of people who make a submission in five minutes and then don't really think about it. And don't submit technical ideas, but rather wishes." (D).

Coping strategies. To tackle the challenge of poor idea quality, the interviewees emphasized the importance of community managers as facilitators. Even though a contest received many ideas (more than 600 ), the community managers engaged with the ideators during the idea generation phase and provided them with additional support in order to reflect on and improve their ideas: "We also discussed and did a lot of community management and asked: How do you exactly imagine it? What do you mean by it? How could it work?" (D). When idea descriptions were too short additional information was requested from the ideators to enable effective evaluation: "If [the idea] is about an app that I didn't understand from the implementation point of view, I contacted the ideator again, with the request to explain it." (L).

In later stages, when the submission period was over, the poor quality ideas were strictly evaluated and immediately eliminated: "If someone just uploads a product sheet, it is not a business plan. This is something we kick out" (Y). Such elimination rounds helped organizers to quickly reduce the size of the idea set to ease subsequent in-depth evaluation.

IT features. To detect ideas with poor quality easier and facilitate work efficiency, the interviewees recommended performing pairwise comparisons (A, D, I). Pairwise comparison is an idea presentation mode that displays two ideas at a time. This mode allows the raters to compare similar ideas and eliminate those that do not meet the contests' evaluation criteria. Additionally, appointing community managers for effective communication with the ideators and the improvement of the idea description requires extra workforce that often is not available. One solution to that is the implementation of a system that automatically detects missing information and asks the ideator for further elaboration (V), i.e., an automated facilitator.

Furthermore, by considering additional idea attributes (e.g., number of likes, comments, idea complexity score), raters can detect poor idea description and acquire a holistic overview of how other experts and/or the crowd perceive the idea. As soon as the idea attributes are aggregated (AF, O), the raters can filter the ideas according to the attribute they are most interested in (C) or automatically rank the ideas according to specific criteria $(\mathrm{N}, \mathrm{R})$. Text mining techniques, i.e., sentiment analysis on the idea's comments $(\mathrm{O})$ can provide an overview of the general perception (approval/disapproval) of the idea by the crowd.

Table 2 summarizes the design element with associated emergent challenges, potential coping strategies, and corresponding IT features.

Table 2. Design element "ideas"

\begin{tabular}{|c|c|c|c|c|}
\hline \multicolumn{5}{|c|}{ Design element } \\
\hline $\begin{array}{l}\text { Number of } \\
\text { ideas }\end{array}$ & $0-50$ & $51-100$ & $101-300$ & $>\mathbf{3 0 0}$ \\
\hline $\begin{array}{l}\text { \# of cases / } \\
\text { goal }\end{array}$ & 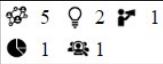 & 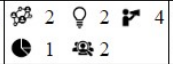 & 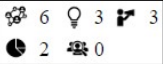 & $\left|\begin{array}{llllll}8 & 2 & 0 & 6 & \boldsymbol{p} & 1 \\
0 & 1 & 9 & 1 & & \end{array}\right|$ \\
\hline $\begin{array}{l}\text { Emergent } \\
\text { challenges }\end{array}$ & \multicolumn{2}{|l|}{ Coping strategies } & \multicolumn{2}{|l|}{ IT feature } \\
\hline $\begin{array}{l}\text { High } \\
\text { quantity of } \\
\text { ideas }\end{array}$ & \multicolumn{2}{|c|}{$\begin{array}{l}\text { - Categorize ideas } \\
\text { - Structure ideas (merge, split, } \\
\text { rephrase) } \\
\text { - Immediate elimination of ideas }\end{array}$} & \multicolumn{2}{|c|}{$\begin{array}{l}\text { - Text mining techniques (keyword } \\
\text { extraction, clustering) } \\
\text { - Standardized submission forms } \\
\text { - Automated elimination }\end{array}$} \\
\hline $\begin{array}{l}\text { Poor idea } \\
\text { description }\end{array}$ & \multicolumn{2}{|c|}{$\begin{array}{l}\text { - Appoint community managers } \\
\text { - Request additional information }\end{array}$} & \multicolumn{2}{|c|}{$\begin{array}{l}\text { - Automated facilitator } \\
\text { - Automated rating aggregates } \\
\text { - Filter/Sorting/Ranking } \\
\text { - Text mining techniques (e.g., } \\
\text { sentiment analysis on comments) } \\
\text { - Pairwise comparison }\end{array}$} \\
\hline
\end{tabular}




\subsection{Design element "raters"}

Design element. The second design element, "raters" refers to the composition of the people responsible for evaluating ideas, i.e., the raters. We categorized this element according to the number of raters involved (1-5, 6-15, >15), their expertise (domain expert, generalist, novice), and their involvement (internal, external, both). In most cases, the evaluation of the submitted ideas was performed by six to 15 raters. Interestingly, the number of raters appears to be dependent on the contest goal. Contests that aimed to "promote entrepreneurship", relied on a rather small number of raters (fewer than five).

Organizations typically employed rater teams that consisted of domain experts $(81 \%)$ and generalists (61\%) with a high level of expertise. We observed a tendency towards higher expertise regardless of the contest goal. Only in $26 \%$ of the cases, novices obtained the role of a rater, mainly when the goal was to "collect innovative idea(s)". In many cases, these novices were the ideators themselves that could submit and evaluate ideas. On the contrary, novices were not consulted when the goal was to "explore market opportunities", as this might require strategic decision-making skills and values that are in line with the companies' vision [3].

In the majority of the cases (52\%), the involvement of the raters was internal, meaning that the raters were employed at the organization that sponsored the contest. In $39 \%$ of the cases, external raters accompanied internal raters, and in $6 \%$ of the cases, only external raters were consulted. Hence, the external crowd or experts were usually involved complementary to internal raters, if at all. This hybrid solution was popular most likely because external raters could provide unique insights into the value of an idea [3]. However, when it comes to goals like "find talent(s)" or "explore market opportunities", contest organizers relied on internal raters as their incentives were aligned with the companies' goals and they wouldn't end up "buying a pig in a poke" [3]. For the design element "raters", we identified lack of expertise and lack of consensus as the major emergent challenges.

Emergent challenge - lack of expertise. Although many contest organizers valued the background diversity among the raters, they also had to cope with a lack of technical expertise. Lack of expertise became apparent when ideas were inadequately allocated. In these cases, the contest organizers often encouraged the raters to provide their impression and some general feedback despite the lack of domain knowledge: "I think there were 1-2 comments, saying "I don't know if this is the right idea for me." Then we said: "ok, just skip this idea and evaluate another one. Nevertheless, read it through and feel free to provide some feedback." (P).
Coping strategies. To cope with lack of expertise, one of the strategies adopted by the raters was to consider feedback attributes, such as number of votes or likes: "I just looked at it, and if I wasn't really sure about the idea, then I used [the community voting] as an indicator."(D). The idea attributes demonstrated the level of popularity and often served as a good indicator of the quality of an idea.

When ideas involved different areas of expertise, contest organizers distributed ideas with specific topics to the raters who could better assess them: "One is expert in the field of healthcare, so he will evaluate the healthcare ideas, the others have broader expertise, so they will distribute the rest of the ideas among each other." (X). One of our interviewees emphasized the importance of specifying the domain of the innovation contest to appoint the right people in the evaluation phase: "You have to really focus because then you really know whom you have to involve as evaluators, whom you have to involve as experts." (J). While focusing the contest theme to a narrow domain allows appointing the appropriate raters, it can also be a risky undertaking as organizations fear that they may prevent potential contributors from submitting their ideas when the campaign is too focused.

Moreover, raters asked for an expert opinion; someone who had the required knowledge to assess ideas, when the raters themselves were uncertain about the quality of ideas: "When I hear someone super critical saying: "So the way you pictured this [idea], it cannot work at all!", I also asked the engineer in our team: "Can you explain to me if this could technically work?"' (M). By following this approach, the raters not only felt more confident about the final assessment, but also had the opportunity to acquire new knowledge. The diverse background allowed raters to bring in different opinions and expertise and complement the assessment. In many cases, it was argued by our interviewees that such diversity was valuable, as they could consult more knowledgeable colleagues when needed and acquire various perspectives. However, the success of external consultation depended heavily on the expert availability and readiness to assist and was not taken for granted. This often resulted in extra time and additional human resources that initially were not planned.

IT features. To cope with the lack of expertise, practitioners suggested a number of IT features. For innovation contests with complex topics, additional information is helpful. Our interviewees (A, M, N, R, X, AA) recommended that having access to information such as the ideator's profile, existing patents, market situation, and competitive environment, could ease the evaluation process. We argue that advanced automated solutions such as virtual assistants could potentially provide a useful information base. Automation of 
information acquisition can complement raters' knowledge and reduce task complexity.

Furthermore, smarter idea allocation is an appropriate solution to deal with lack of expertise. Through automated idea distribution (AB) and profile matching (L), the ideas are efficiently distributed among the raters and matched with the raters' interest or level of expertise in a particular topic.

Emergent challenge - lack of consensus. Another common challenge identified concerning the design element raters is the lack of consensus during assessment: "We realized that customer value and market potential are difficult to assess. If you would ask three people, you will probably get different opinions." (D). The raters often expressed diverse opinions not only about the content, the quality, or potential of an idea, but also when discussing the evaluation criteria. The different interpretations of the evaluation criteria resulted in confusion and long discussions until consensus, if at all, was reached.

Coping strategies. To handle the lack of consensus, the contest organizers described several coping strategies. First, the standardization of the selection criteria, through detailed descriptions and explanations in a criteria catalogue, aimed at developing a shared understanding among raters and faster reach of consensus: "We had some people using [the criteria catalogue] all over the place, we wanted to standardize it and give them exact description of what it means when we say "low" for competitive advantage." (AF). In addition, expert ratings were aggregated to smooth the different opinions among experts: "There are people who evaluate positively, and people who evaluate negatively. And if you calculate an average from this group, the different evaluations are normalized." (AB). Even after the ratings were aggregated, raters often engaged in discussions to ensure consensus: "We looked at the ranking and asked whether it corresponds to our opinion, how we would rank [the idea]. Then it was discussed." (AA). Last, a holistic assessment was often proposed as an effective way to evaluate ideas, especially when C-level executives held the rater role. Such a holistic assessment did not require a strict evaluation according to formal criteria but was built on constructive discussion: "I think the discussion is always pretty general. It's not really focused on specific criteria. Especially on the C-level, they're hard to guide with evaluation criteria." (O).

IT features. To avoid the lack of consensus, the interviewees proposed a holistic assessment of the ideas through a binary yes/no rating system $(\mathrm{N})$ that relies on the overall potential of the idea instead of isolated criteria. If the contest organizers decide to rely on designated criteria, a comprehensive description could be provided on the evaluation platform for clarification purposes (I). This could be further enhanced by virtual
Table 3. Design element "raters"

\begin{tabular}{|c|c|c|c|c|}
\hline \multicolumn{5}{|c|}{ Design element } \\
\hline $\begin{array}{l}\text { Number of } \\
\text { raters }\end{array}$ & $1-5$ & \multicolumn{2}{|c|}{$6-15$} & $>15$ \\
\hline $\begin{array}{l}\# \text { of cases / } \\
\text { goal }\end{array}$ & 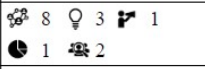 & \multicolumn{2}{|c|}{ 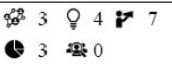 } & 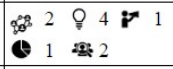 \\
\hline $\begin{array}{l}\text { Expertise of } \\
\text { raters }\end{array}$ & Domain experts & \multicolumn{2}{|c|}{ Generalist } & Novice \\
\hline $\begin{array}{l}\text { \# of cases / } \\
\text { goal }\end{array}$ & 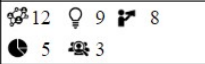 & \multicolumn{2}{|c|}{ 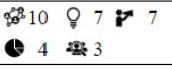 } & 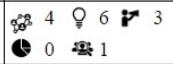 \\
\hline $\begin{array}{l}\text { Involvement } \\
\text { of raters }\end{array}$ & Internal & \multicolumn{2}{|c|}{ External } & Both \\
\hline $\begin{array}{l}\text { \# of cases / } \\
\text { goal }\end{array}$ & 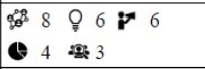 & $\begin{array}{ll}2 \\
8\end{array}$ & $\boldsymbol{p} 0$ & 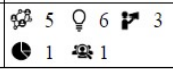 \\
\hline $\begin{array}{l}\text { Emergent } \\
\text { challenges }\end{array}$ & \multicolumn{2}{|l|}{ Coping strategies } & \multicolumn{2}{|c|}{ IT feature } \\
\hline $\begin{array}{l}\text { Lack of } \\
\text { expertise }\end{array}$ & \multicolumn{2}{|c|}{$\begin{array}{l}\text { - Consider idea feedback } \\
\text { - Ask for experts/others opinion } \\
\text { - Distribute and cluster ideas }\end{array}$} & \multicolumn{2}{|c|}{$\begin{array}{l}\text { - Virtual assistants for automated } \\
\text { information aquisition } \\
\text { - Automated idea distribution } \\
\text { - Profile matching }\end{array}$} \\
\hline $\begin{array}{l}\text { Lack of } \\
\text { consenus }\end{array}$ & \multicolumn{2}{|l|}{$\begin{array}{l}\text { - Standardize criteria } \\
\text { - Train raters } \\
\text { - Engage in discussions } \\
\text { - Aggregate ratings } \\
\text { - Perform holistic assess1 }\end{array}$} & \multicolumn{2}{|c|}{$\begin{array}{l}\text { - Virtual assistants for evaluation } \\
\text { facilitation } \\
\text { - Binary rating system }\end{array}$} \\
\hline
\end{tabular}

assistants that remind the raters of the evaluation steps and provides a detailed description of the criteria or concrete examples of the rating scale $(\mathrm{M})$.

Table 3 summarizes the design element "raters" with its emergent challenges, potential coping strategies and corresponding IT features.

\subsection{Design element “duration”}

Design element. The third design element, "duration", refers to the time needed for evaluating and selecting ideas. In the majority of the cases (55\%), the duration of the shortlisting process was between two and three weeks. In many cases (42\%) it lasted about one to two weeks, one third (35\%) took more than three weeks, and only $25 \%$ were completed in a short time frame of less than one week. The study participants emphasized that shortlisting is a time-consuming process that requires high effort and many resources. The duration depends on several factors like the number of submitted ideas, the availability of the raters, the raters' workload aside from the contest, just to name a few. While no concrete associations can be extracted between goal and duration, we observed that the shortlisting process of contests that aimed to "collect innovative idea(s)" usually lasted between two and three weeks, unlike contests that aimed to "explore market opportunities", where the shortlisting process usually took more than three weeks. We infer that the utilization of a submission platform for many of the cases with the goal to "collect innovative ideas" might have accelerated the evaluation as the selection process was standardized and many challenges as reported before could be effectively avoided.

Emergent challenge - lack of preparation. Almost all contest organizers reported that time-pressure was a serious challenge. In one case, the shortlisting phase had 
to be considerably extended until all the ideas were properly evaluated, while in another case, the duration of the shortlisting meeting lasted only some hours. These short but intense meetings though led to limited concentration, and once the cognitive resources of the participants were depleted, the discussion became inefficient.

The inefficiencies during the evaluation process were often linked to lack of preparation. In many cases with the goal to "collect innovative idea(s)" the raters didn't take the time to read and perform an initial assessment of the assigned ideas: "We always find out some experts didn't evaluate, they didn't take the time." (O). Our study participants explained that even when the ideas were allocated to the raters accordingly, many of them could not read the ideas in detail due to the heavy workload: "They got these ideas sent as .pdf and they could read through them. I'm not sure to what extent they did that because they have a lot to do." (Q). Lack of preparation was also associated with the professional role of the raters, as C-level executives had several other priorities that kept them busy: "In the jury meeting, you can expect that nobody has ever seen the idea, never been on the platform or anything, because these are like "C-level" and they just don't prepare." (O).

Coping strategies. To manage the lack of preparation, contest organizers sent constant reminders to the raters: "You give them the task, they log on the platform, read it through, evaluate it, and they have a lot to do, then we have to remind them again." (D). When raters still didn't take the time to read the ideas even after several reminders, the contest organizers deployed other solutions to ensure a certain level of preparation. Briefings and updates provided the necessary information before shortlisting sessions: "I just brief them because they would not have time to read all the ideas.” (E). Idea booklets were also proposed as an effective solution. Such booklets included all the essential information of each idea and provided a comprehensive overview: "We also do booklets for each of the meetings, so they get a printed booklet with all of the ideas, so they can actually go through it and read all of the ideas and can make notes during the presentation.”(O). The drawback of these booklets was that they required extra work by the contest organizers, but didn't necessarily achieve the expected outcome.

IT features. Technology can significantly facilitate a smooth workflow of the evaluation process and increase work efficiency. Several study participants emphasized the usefulness of a tool that can aggregate the idea information and generate summarized reports (S, T, AF, AA, B, W, O, Q). Such reports can provide the most important information and save considerable time for both the raters and the contest organizers. Automated reminders (Y) can inform the raters when the submitted ideas are updated and remind them to
Table 4. Design element "duration"

\begin{tabular}{|c|c|c|c|c|}
\hline \multicolumn{5}{|c|}{ Design element } \\
\hline $\begin{array}{l}\text { Shortlisting } \\
\text { duration }\end{array}$ & $<1$ week & 1 - 2 weeks & 2 - 3 weeks & $>3$ weeks \\
\hline $\begin{array}{l}\# \text { of cases / } \\
\text { goal }\end{array}$ & 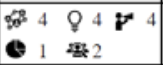 & 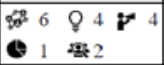 & 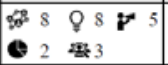 & 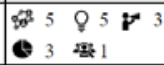 \\
\hline $\begin{array}{l}\text { Emergent } \\
\text { challenges }\end{array}$ & \multicolumn{2}{|l|}{ Coping strategies } & \multicolumn{2}{|l|}{ IT feature } \\
\hline $\begin{array}{l}\text { Lack of } \\
\text { preparation }\end{array}$ & \multicolumn{2}{|c|}{$\begin{array}{l}\text { - Send reminders } \\
\text { - Brief and update } \\
\text { - Create idea booklets }\end{array}$} & \multicolumn{2}{|c|}{$\begin{array}{l}\text { - Automated reminders } \\
\text { - Progress tracking } \\
\text { - Workflow tool for summarized idea } \\
\text { reports }\end{array}$} \\
\hline
\end{tabular}

complete their evaluation in time. Real-time tracking of the evaluation progress $(\mathrm{P})$ can facilitate time management and allow a better organization of the selection process.

Table 4 summarizes the characteristics of design element "duration” with its emergent challenges, coping strategies and associated IT features.

\section{Framework for successful idea selection}

Open innovation initiatives can provide great benefits to organizations. However, these initiatives are a complex undertaking and require a clear understanding of the goal, adequate knowledge on how to design the process, and alternative coping strategies to deal with emergent issues. Through our qualitative interview study, we uncovered different contest goals, emergent challenges that are associated with contest design elements and manual and IT-based coping strategies to tackle the identified challenges.

We argue that many of the emergent challenges can be managed efficiently or be minimized, with a clear focus on and understanding of the goal of the innovation contest. Besides the recommendation to set concrete contest goals, this paper provided a range of manual solutions that can support effective management of the emerging challenges. We are aware that not every organization is willing to invest in new technology, unless they see a clear benefit from the results of the contest. Thus, manual strategies can be easily implemented according to emergent challenges.

We also provide automated solutions that can prove helpful according to the individual needs and alleviate the selection process. As in one example, drastic elimination of ideas can be automated; as soon as the ideas do not meet the minimum requirements, like an attached design, automated elimination can take place. In contrast, innovation contests that aim to achieve more subjective goals like finding talent or promoting entrepreneurship, need to think of different ways of assessment. In such cases, automated facilitators and virtual assistants can support the raters, for example, by asking for or finding additional relevant information, and reduce the required duration. 
Figure 2 summarizes what we have found out about the goals, design elements, emergent challenges, and coping strategies relevant to idea selection into a comprehensive guiding framework that can assist contest organizers in navigating the various possibilities of open innovation initiatives. The five contest goals provide a more nuanced picture of what potential benefits organizations can realize when engaging in innovation contests. The identified design elements "ideas", "raters", and "duration" allow organizations to understand better how to design their idea selection processes in accordance with the contest goal to achieve the intended benefits. The guiding framework further recommends coping strategies that practitioners adopt to tackle these emergent challenges.

As many coping strategies require much manual effort, we also identified opportunities for digitalization of selection process activities. We deem the technological progress in artificial intelligence, e.g., natural language processing or machine learning, as an enabler to develop automated services that can assist, not replace, individuals during idea selection.

\section{Acknowledgements}

The research leading to the presented results was funded by the Austrian Science Fund (FWF): P 29765.

\section{References}

[1] J. Nieminen, 50+ statistics on innovation - What do the numbers tell us?, 2018, retrieved 6.6.2019, https://www.viima.com/blog/innovation-stats.

[2] J. Birkinshaw, C. Bouquet, and J. Barsoux, "The 5 myths of innovation", MIT Sloan management review, 2011, 52(2).

[3] A. King and K.R. Lakhani, "Using Open Innovation to Identify the Best Ideas.", MIT Sloan Management Review, 2013, 55(1), pp. 41-48.

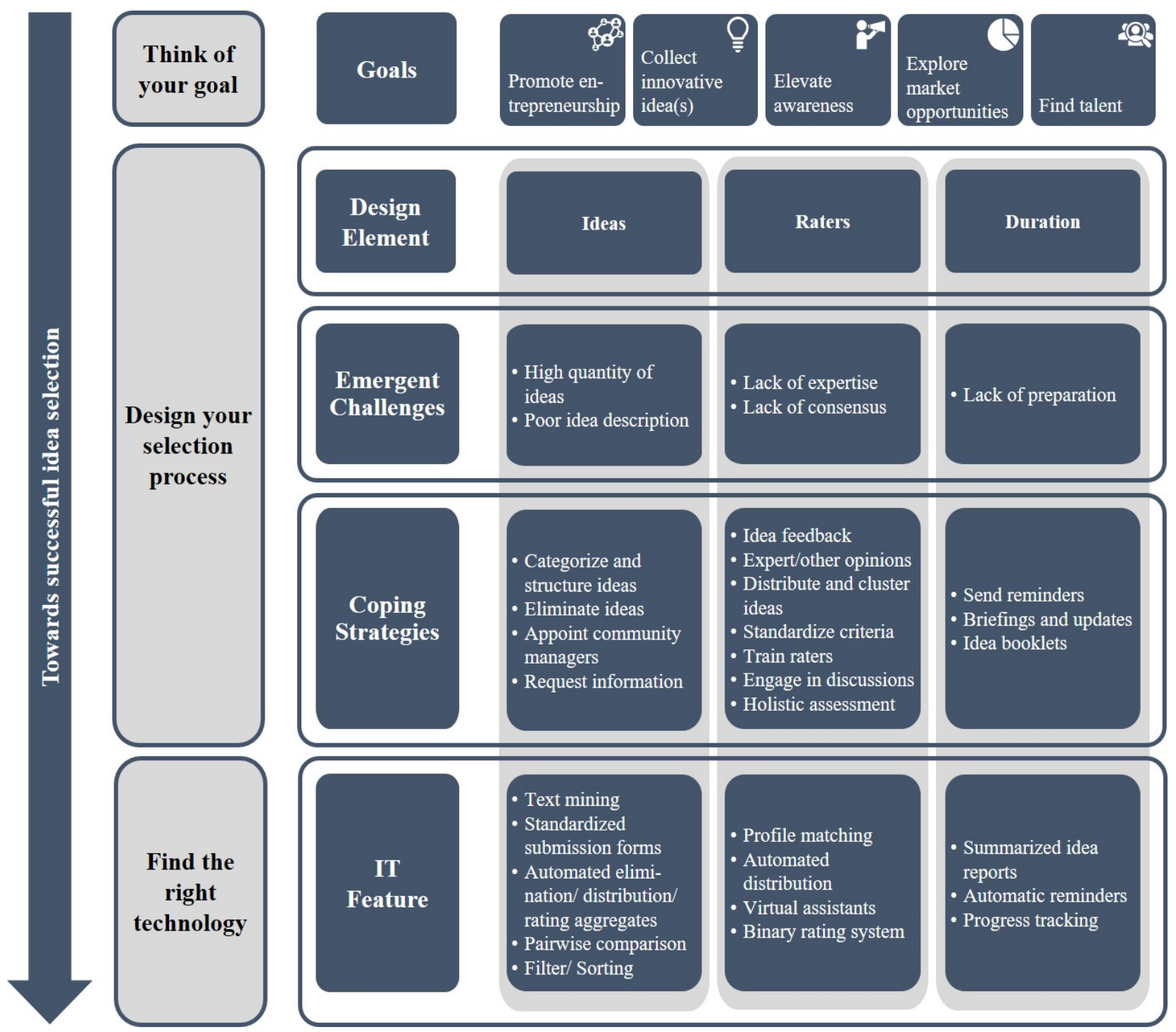

Figure 2. A guidance framework for successful idea selection 
[4] M. Rass, M. Dumbach, F. Danzinger, A.C. Bullinger, and K.M. Moeslein, "Open innovation and firm performance: the mediating role of social capital", Creativity and innovation management, 2013, 22(2), pp. 177-194.

[5] J. Grönlund, D.R. Sjödin, and J. Frishammar, "Open innovation and the stage-gate process: A revised model for new product development", California management review, 2010, 52(3), pp. 106-131.

[6] M. Antikainen, M. Mäkipää, and M. Ahonen, "Motivating and supporting collaboration in open innovation", European Journal of Innovation Management, 2010, 13(1), pp. 100-119. [7] D.C. Brabham, "Crowdsourcing as a model for problem solving: An introduction and cases", Convergence, 2008, 14(1), pp. 75-90.

[8] A. Ghezzi, D. Gabelloni, A. Martini, and A. Natalicchio, "Crowdsourcing: a review and suggestions for future research", International Journal of Management Reviews, 2018, 20(2), pp. 343-363.

[9] T.W. Malone, R. Laubacher, and C. Dellarocas, "The collective intelligence genome", MIT Sloan Management Review, 2010, 51(3), pp. 21.

[10] E. von Hippel, Open User Innovation, The encyclopedia of human-computer interaction., J.M. Carroll and J. Kjeldskov, Editors, 2013.

[11] R.O. Briggs and B.A. Reinig, "Bounded Ideation Theory.", Journal of Management Information Systems, 2010, 27(1), pp. 123-144.

[12] J.B. Haller, A.C. Bullinger, and K.M. Möslein, "Innovation contests", Business \& Information Systems Engineering, 2011, 3(2), pp. 103-106.

[13] I. Blohm, C. Riedl, J.M. Leimeister, and H. Krcmar, "Idea evaluation mechanisms for collective intelligence in open innovation communities: Do traders outperform raters?", Proceedings of 32nd International Conference on Information Systems, 2011.

[14] R.E. Mayer and R. Moreno, "Nine ways to reduce cognitive load in multimedia learning", Educational Psychologist, 2003, 38(1), pp. 43-52.

[15] K. Girotra, C. Terwiesch, and K.T. Ulrich, "Idea generation and the quality of the best idea", Management Science, 2010, 56(4), pp. 591-605.

[16] V. Banken, I. Seeber, and R. Maier, "Comparing Pineapples with Lilikois: An Experimental Analysis of the Effects of Idea Similarity on Evaluation Performance in Innovation Contests", Proceedings of the 52nd Hawaii International Conference on System Sciences, 2019.

[17] E.F. Rietzschel, B.A. Nijstad, and W. Stroebe, "Productivity is not enough: A comparison of interactive and nominal brainstorming groups on idea generation and selection", Journal of Experimental Social Psychology, 2006, 42(2), pp. 244-251.

[18] R. Santiago Walser, I. Seeber, and R. Maier, "The fewer, the better? Effects of decomposition of information load on the decision making process and outcome in idea selection", Proceedings of the 27th European Conference on Information Systems (ECIS): Stockholm \& Uppsala, Sweden, 2019.

[19] J. Ye and A. Kankanhalli, "Exploring innovation through open networks: A review and initial research questions", IIMB Management Review, 2013, 25(2), pp. 69-82.

[20] I. Seeber, E. Bittner, R.O. Briggs, T. de Vreede, G.-J. de Vreede, A. Elkins, R. Maier, A.B. Merz, S. Oeste-Reiß, and
N. Randrup, "Machines as teammates: A research agenda on AI in team collaboration", Information \& Management, 2019. [21] S. Adamczyk, A.C. Bullinger, and K.M. Möslein, "Innovation contests: A review, classification and outlook", Creativity and Innovation Management, 2012, 21(4).

[22] M.L. Goggin, "The" too few cases/too many variables" problem in implementation research", Western Political Quarterly, 1986, 39(2), pp. 328-347.

[23] A. Przeworski and H. Teune, Research Designs, The Logic of Comparative Social Inquiry. , Wiley-Interscience: New York, London, Toronto, Sydney, 1970, pp. 31-46.

\section{Appendix}

We conducted 34 semi-structured interviews between May 2017 and March 2018 in 31 unique casesettings. Each of the 31 cases is identified by a letter (Table 1). Our interview guideline was informed by topics such as the expectations and goals of the innovation contest, and details about the selection process. After conducting two pilot interviews, we slightly revised the guideline for improved clarity. The interviews were conducted face-to-face, via telephone or via web-conferencing. They lasted between 44 and 100 minutes, with 72 minutes on average. We selected the candidates purposively according to the following criteria: 1) The idea selection process had to be completed; 2) Submissions had to be qualitative (e.g., ideas, business plans); 3) the process of selection needed to involve a complex deliberation.

Our sample of innovation contests varied based on the organization type (e.g., self-hosted or intermediary), target group (public or restricted), number of submissions (few to many), and online contest platform (available and not available). We aimed for maximum variation within the sample and maximized the differences between the cases except for the phenomena to be explained [22, 23].

The interviews were performed in English or German and the appropriate text passages were translated. Several rounds of coding followed, in which we especially focused on the goal(s), setting, emerging challenges, and coping strategies. Five researchers coded all interviews based on a shared codebook to increase internal validity. Eleven interviews were coded and compared by two researchers.

This study has some limitations that need to be considered. First, when identifying the different goals of innovation contests, only those explicitly mentioned were considered. Therefore, implicit goals or hidden agendas that could very well have influenced the process were not taken into consideration. Furthermore, we only had one interviewee per case for most of our cases. This limitation implies that the acquired information result from a single perspective and might hinder an in-depth look into certain aspects. 